\title{
ПРОТОТИПИРОВАНИЕ СИСТЕМЫ ДИНАМИЧЕСКОЙ ТЕРМОРЕГУЛЯЦИИ: ВЫБОР КОМПОНЕНТОВ ДЛЯ ДЕМОНСТРАЦИОННОГО ПРОТОТИПА
}

\section{PROTOTYPING A DYNAMIC THERMOREGULATION SYSTEM: SELECTING COMPONENTS FOR A DEMONSTRATION PROTOTYPE}

I. Vasiliev

Summary. This article raises questions about the relevance of research in the field of wearable devices, expanding the functionality of clothing with the help of innovative solutions. A brief description of the innovative start-up project "Mneima" is given. An overview of the components used in the prototyping of the dynamic thermoregulation system is presented. This work is of practical importance, since it significantly reduces the time for selecting components for creating innovative solutions in the field of wearable devices with a thermoregulatory function. The relevance is due to the significant growth of the wearable device market.

Keywords: wearable electronics, smart clothes, prototyping, thermoregulation.

\author{
Васильев Игорь Сергеевич \\ Специалист, ГБПОУ «Уфимский Колледж \\ Радиоэлектроники, Телекоммуникаций \\ и Безопасности» \\ stormcreator@inbox.ru
}

Аннотация. В данной статье поднимается вопросы 06 актуальности исследовательских работ в сфере носимых устройств, расширение функциональности одежды при помощи инновационных решений. Приведено краткое описание инновационного стартап-проекта "Mneima". Представлен обзор на компоненты, используемые в ходе создания прототипа системы динамической терморегуляции. Данная работа имеет практическую значимость, поскольку значительно сокращает время на выбор компонентов для создания инновационных решений в сфере носимых устройств с функцией терморегуляции. Актуальность обусловлена значительным ростом рынка носимых устройств.

Ключевые слова: носимая электроника, умная одежда, прототипирование, терморегуляция.

\section{Введение}

B настоящее время рынок «умной» одежды (Wearable Technology - WT) развивается быстрыми темпами, и многие известные компании и стартапы ведут разработки в этой области [1]. При этом WT подразумевает интерактивное взаимодействие с окружающей средой: восприятие сигналов, обработку информации, воспроизведение ответных реакций. Взаимодействие WT с окружающей средой происходит с использованием специальных электронных устройств - датчиков, сенсоров, солнечных батарей, нагревательных элементов и т.п. В частности, WT расширяет функциональность одежды, добавляя предмету гардероба какие-либо нехарактерные свойства так, чтобы при этом не нарушались ее обычные функции.

Разработки WT улучшают качество жизни населения. Однако стоимость WT зачастую превышает стоимость обычной одежды из-за сложностей, с которыми приходится сталкиваться разработчикам при интегрировании микроэлектроники в одежду. Тем не менее, с каждым годом стоимость конечного продукта становится ниже благодаря новым исследованиям и разработкам, а также возрастающей конкуренции на рынке [2]. Большую популярность имеет WT с функционалом обогрева пользователя. Но в некоторых ситуациях [3] более полезной будет функция охлаждения, которая на данный момент встречается редко. Следовательно, исследовательская работа в этой сфере является актуальной.

\section{Проект и прототипирование}

Проект «Mneima» предполагает создание умной одежды с встроенной функцией поддержания комфортного температурного режима посредством обогрева и охлаждения ограниченного пространства между телом человека и одеждой, а также зон непосредственного прилегания к телу человека. Реализуется данный функционал при использовании эффекта Пельтье. Работы по проекту велись при поддержке и консультировании специалистов центра прототипирования радиоэлектронного кластера Республики Башкортостан (РЭК РБ). Впервые проект был представлен в 2017 году, при- 

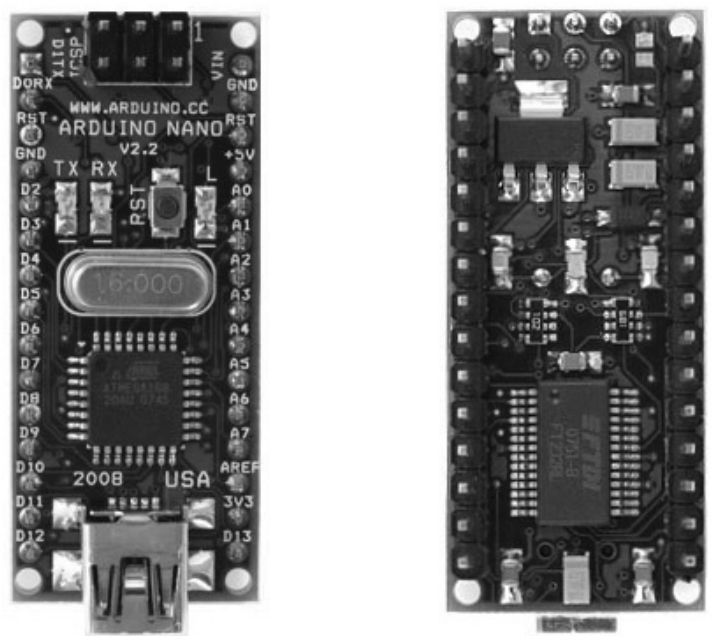

Pис. 1. Arduino Nano

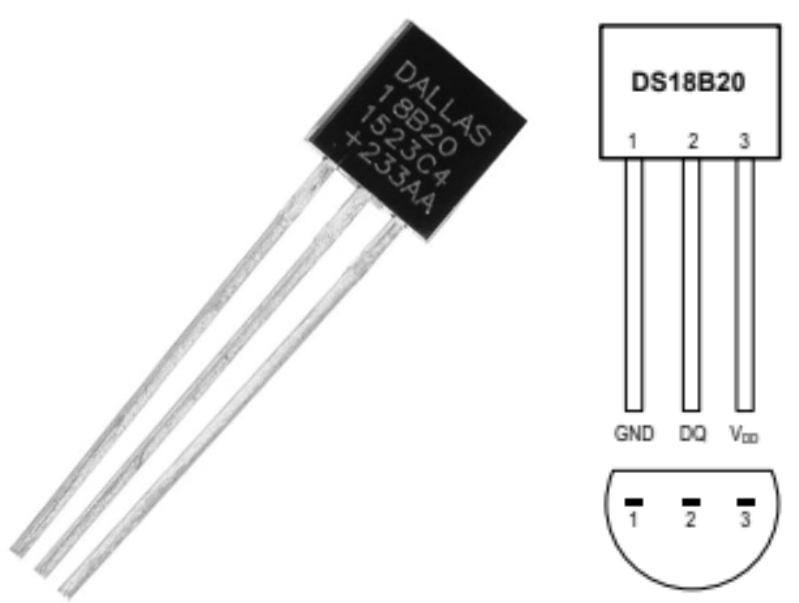

Рис. 2. Датчик Dallas Semiconductor ds $18 \mathrm{~b} 20$

нимал участие в конкурсе "УМНИК-2017". До 2019 года на рынке не было представлено умной одежды с подобным функционалом.

В ходе разработки проекта возникла необходимость создания демонстрационного прототипа системы динамической терморегуляции (далее - СДТ). СДТ это программно-аппаратный комплекс способный динамически изменять температуру окружающей среды в месте применения.

В разработке прототипа СДТ использовались следующие составляющие:

1. Микроконтроллер ATmega328P на плате Arduino Nano (Рис. 1). Это удобный и компактный модуль управления электронными компонентами, а также приемом и передачи данных. Благодаря C-по- добному языку программирования достигается полноценная совместимость с программным обеспечением, написанным на языке $\mathrm{C}++$.

2. Датчики температуры и влажности Dallas Semiconductor ds18b20 (Рис. 2). Для полноценного тестирования прототипа необходимо уточнять параметры температуры и влажности, поскольку в средах с разницей влажности в несколько процентов температура окружающей среды ощущается по-разному.

3. Набор электронных компонентов для создания сглаживающего фильтра. Сглаживающий фильтр необходим для снижения уровня пульсаций тока при управлении через ШИМ [9].

4. Персональный компьютер с предустановленной средой разработки ПО. В качестве среды разработки программной составляющей был выбран 


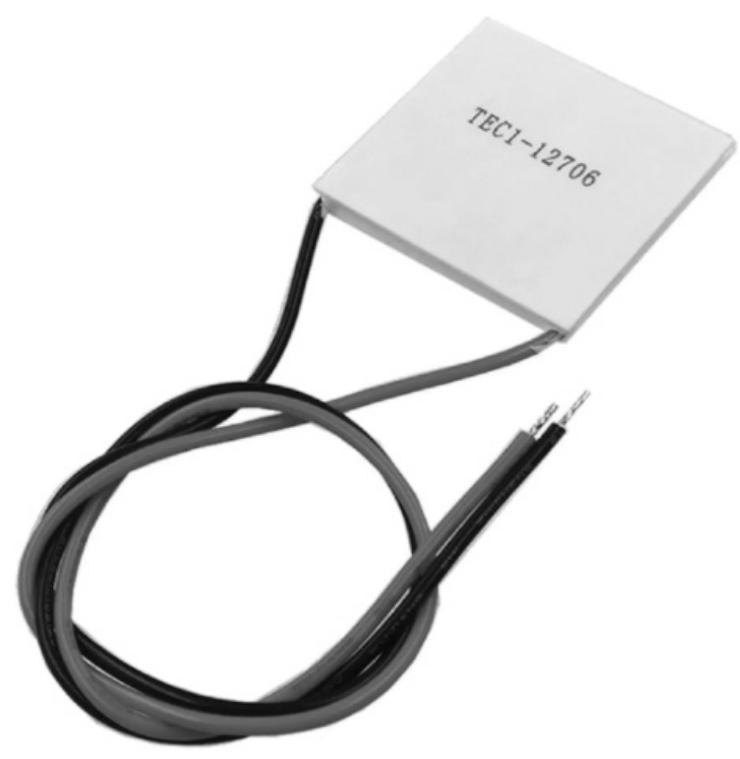

Рис. 3. Элемент Пельтье

Visual Studio. Программа с пользовательским интерфейсом для тестирования прототипа СДт была разработана на языке программирования - $\mathrm{C}++$, разработка запатентована [10]. Для удобной модификации и развития программного обеспечения тестирования прототипов - программистом были внедрены алгоритмы с поддержкой непрерывной интеграции [11]. Разработка программного обеспечения отдельно описана в и опубликована в научном журнале [12].

5. Элементы Пельтье. В качестве основного действующего компонента СДТ было принято решение выбрать элементы Пельтье, поскольку они обладают возможностью перенаправлять тепловую энергию, тем самым нагревать или охлаждать прилегающую поверхность. Кроме того размеры элемента могут быть весьма компактны - в нашем случае использовался элемент 40×40 мм.

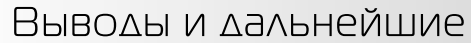 перспективы исслеАования}

Процесс выбора компонентов для сборки и тестирования прототипа может занимать довольно много времени, поскольку далеко не все необходимое может находиться в ближайшем доступе. Однако именно такой список показался оптимальным, поскольку эти элементы довольно распространены, а также имеют оптимальные характеристики - размер, энергоэффективность и функциональность. Прототипирование демонстрационного образца позволило в короткие сроки достичь поставленных целей, а именно - исследовать работу СДТ в различных условиях, подобрать наиболее эффективный алгоритм работы и продемонстрировать жизнеспособность идеи использования эффекта Пельтье как основы проекта "Mneima".

\section{ЛИТЕРАТУРА}

1. Стенькина, М.П. Исследование рынка носимой электроники / М.П. Стенькина // Фундаментальные и прикладные исследования в науке и образовании: сборник статей Международной научно-практической конференции, Тюмень, 05 июня 2019 года. - Тюмень: Общество с ограниченной ответственностью «Аэтерна», 2019.- - С. 78-81.

2. Наговицына, М.А. Прямое и косвенное влияние природных факторов на психическое состояние спортсменов / М.А. Наговицына, А.С. Колегова, Д.Ю. Невоструев // Актуальные подходы и направления научных исследований XXI века: Материалы Международной (заочной) научно-практической конференции [Электронный ресурс], Кишинев, 25 октября 2016 года / Под общей редакцией А.И. Вострецова.— Кишинев: Научно-издательский центр «Мир науки» (ИП Вострецов Александр Ильич), 2016. - С. 84-91.

3. Михайлова, И.Д. Исследование влияния изменения климатических факторов на тепловое состояние человека / И.Д. Михайлова, Л.А. Осипенко, К.А. Михайлов // Вестник научных конференций. - 2017. - № 1-2(17). - С. 83-85.

4. Кочетов, 0.С. Способы оценки комфортности рабочей зоны / 0.С. Кочетов // Безопасность труда в промышленности. — 2012.— № 4. - С. 27-30.

5. Кочетов 0.С., Стареева М.О., Стареева М.М. Способ оценки комфортности рабочей зоны по параметрам микроклимата.— 2014. 
6. Гринкевич, В.А. Синтез регулятора тока для термостолика на основе элемента Пельтье / В.А. Гринкевич // Сборник научных трудов Новосибирского государственного технического университета. — 2019. — № 3-4(96). — С. 33-52. — D0I 10.17212/2307-6879-2019-3-4-33-52.

7. GU J., LI B. Design of Multi Point Temperature Monitoring System Based on DS18B20 //Electronic Science and Technology. — 2018. — C. 03.

8. Saha R. et al. A Working Prototype Using DS18B20 Temperature Sensor and Arduino for Health Monitoring //SN Computer Science. — 2021.— T. 2. — № . 1.- C. 1-21.

9. Тихомиров, А.К. ШИМ-регулятор для термоэлектрического модуля Пельтье / А.К. Тихомиров // Молодежь XXI века: шаг в будущее: материалы XXI региональной научно-практической конференции: в 4 т., Благовещенск, 20 мая 2020 года. - Благовещенск: Дальневосточный государственный аграрный университет, 2020.- С. 224-225.

10. Свидетельство о государственной регистрации программы для ЭВМ № 2020664361 Российская Федерация. Программное обеспечение системы динамической терморегуляции для носимой электроники (Mneima-type control program), версии 2.0: № 2020663669: заявл. 06.11.2020: 0публ. 12.11.2020 / Р.Г. Манаев.

11. Манаев, Р.Г. Технология внедрения непрерывной интеграции в крупных высоконагруженных системах с минимизацией ошибок и временных потерь со стороны разработчиков / Р.Г. Манаев // Инновации и инвестиции. — 2020.— № 12. — С. 127-130.

12. Манаев, Р.Г. Разработка программного обеспечения системы динамической терморегуляции для носимой электроники / Р.Г. Манаев, И.С. Васильев // Современная наука: актуальные проблемы теории и практики. Серия: Естественные и технические науки.— 2020. - № 12.— C. $71-79 .-$ D0I 10.37882/2223-2966.2020.12.20.

13. Соболева, Е.К. Система регулирования тока, протекающего через элемент Пельтье / Е.К. Соболева, В.И. Капля // Научно-практическая конференция студентов ВПИ (филиал) ВолгГТУ «Наука молодых: идеи, результаты, перспективы», Волжский, 23-26 мая 2016 года. - Волжский: Волжский политехнический институт (филиал) ФГБОУ В0 «Волгоградский государственный технический университет», 2016. - С. $48-49$.

14. Клочков, К.А. Формирование функции линейного управления ШИМ-преобразователем для непрерывного электропитания массива термоэлектрических элементов в составе универсального технологического комплекса / К.А. Клочков, А.П. Бесшапошникова // Гагаринские чтения - 2019: Сборник тезисов докладов XLV Международной молодежной научной конференции, Москва, Барнаул, Ахтубинск, 16-19 апреля 2019 года / Московский авиационный институт (национальный исследовательский университет). - Москва, Барнаул, Ахтубинск: Московский авиационный институт (национальный исследовательский университет), 2019. - С. 279-280.

15. Самарин, А. Электроника, встроенная в одежду — технологии и перспективы / А. Самарин // Компоненты и технологии. - 2007.- № 4(69).C. 221-228.

(с Васильев Игорь Сергеевич ( stormcreator@inbox.ru).

Журнал «Современная наука: актуальные проблемы теории и практики»

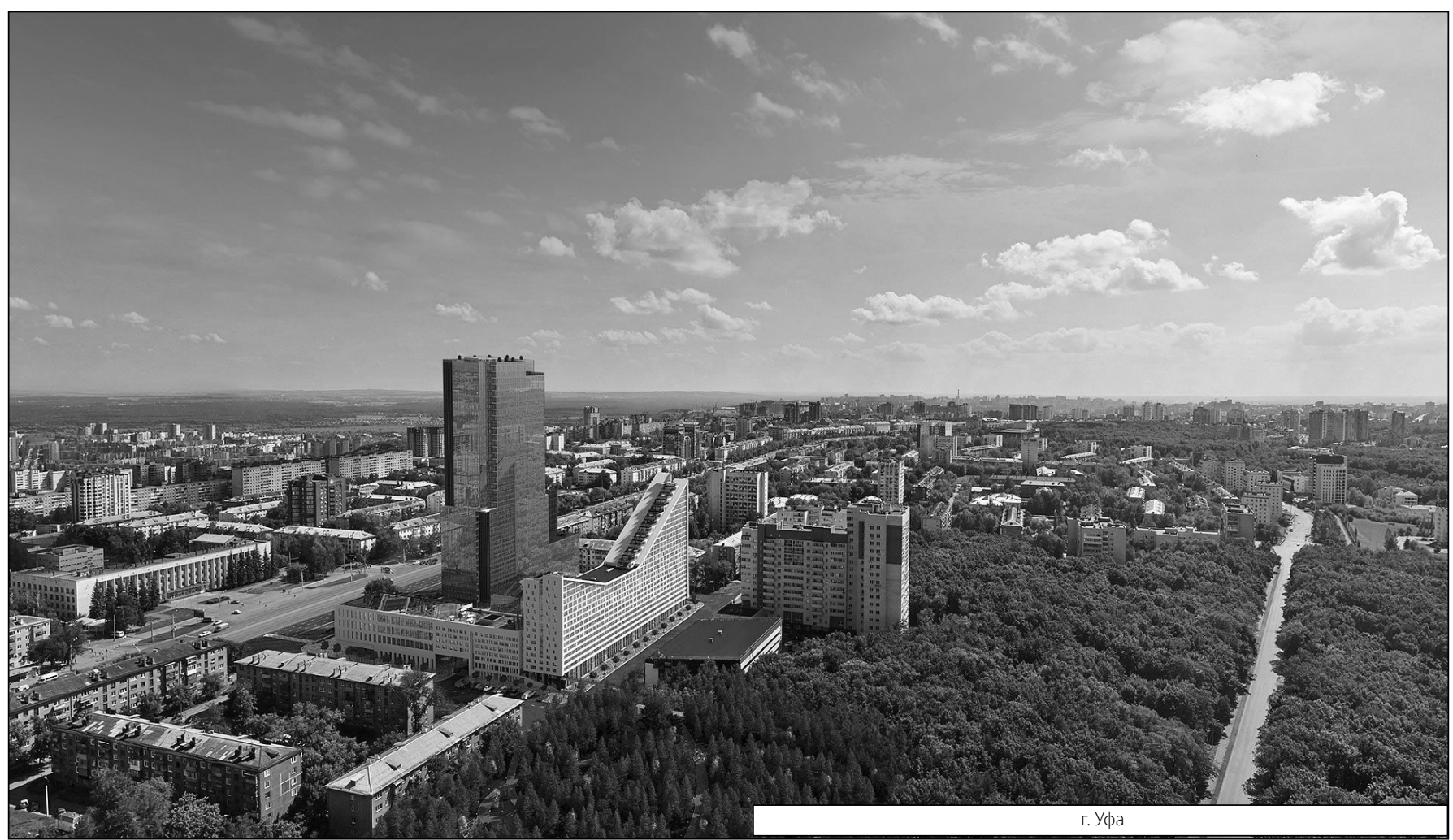

